\title{
SELECCIÓN DE GENOTIPOS DE FRIJOL COMÚN POR SU RESISTENCIA AL TIZÓN BACTERIANO ${ }^{1}$
}

\author{
Odile Rodríguez-Miranda ${ }^{2}$,Juan Carlos Rosas-Sotomayor ${ }^{3}$
}

\section{RESUMEN}

Selección de genotipos de frijol común por su resistencia al tizón bacteriano. En noviembre del 2007, se evaluó la reacción de genotipos de frijol común al tizón común producido por el aislamiento EAP 9506 de $X c p$ de Honduras y se identificaron nuevas líneas y variedades tolerantes a este patógeno. El estudio se desarrolló en el invernadero del área experimental del Programa de Investigaciones en Frijol (PIF), Escuela Agrícola Panamericana, Zamorano, Honduras. Se sembraron dos experimentos: 1) 37 genotipos procedentes de Cuba, 2) 27 genotipos procedentes del PIF de Honduras. Las plantas fueron inoculadas con el método de punción múltiple en la etapa V3. La severidad del daño se evaluó a los 20 días después de la inoculación, utilizando una escala visual de 1 a 9 (1=sin síntomas; 9= síntomas severos). El genotipo que mostró reacción de resistencia a $X c p$ en el experimento 1 fue: XAN 159 ; y en el experimento 2: VAX 3, VAX 5, VAX 6, XAN 309 y XAN 310, y líneas procedentes de la cruza Tío Canela 75/VAX6, destacándose X0104-45-3-5-5, X104-45-5-1-4 y X104-45-5-5-3, con los valores de resistencia más sobresalientes.

Palabras claves: Phaseolus vulgaris, enfermedad bacteriana, Xanthomonas campestris.

\section{ABSTRACT}

Selection of genotypes of common bean for their resistance to common smut. In November of the 2007, the reaction of bean genotypes to the common smut produced by the isolation EAP 9506 of Xcp of Honduras was evaluated, and new lines and tolerant varieties to this pathogen were identified. The study was developed in a greenhouse of the experimental area at Research Program on Bean (PIF), PanAmerican Agricultural School, Zamorano, Honduras. Two experiments were established: 1) 37 genotypes from Cuba, 2) 27 genotypes from the PIF in Honduras. The plants were inoculated at the stage V3 with the isolation EAP9506, using the method of multiple puncturing. The severity of the damage was evaluated 20 days after inoculation, using a visual scale from 1 to 9 (1=no symptoms; 9 = severe symptoms). The genotypes that showed resistance reaction to Xcp in experiment 1 was XAN 159, and in experiment 2, VAX 3, VAX 5, VAX 6, XAN 309 and XAN 310, and lines resulting from the cross Tío Canela 75/VAX6, and with X0104-45-35-5, X104-45-5-1-4 y X104-45-5-5-3 showing outstanding resistance values.

Key words: Phaseolus vulgaris, common smut, Xanthomonas campestris.

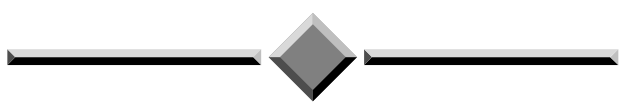

\section{INTRODUCCIÓN}

El tizón bacteriano (Xanthomonas campestris pv. phaseoli) (Smith) Dye (Xcp) es una enfermedad frecuente en muchas de las regiones donde se cultiva el frijol común (Phaseolus vulgaris L.), con la excepción de las regiones muy secas de los trópicos. Las pérdidas en el rendimiento por los daños ocasionados por esta enfermedad, pueden variar entre el 15 al 30\% (Campos 1987), y entre un 20 a $60 \%$ en cultivares susceptibles

\footnotetext{
Recibido: 10 de diciembre, 2009. Aceptado: 22 de noviembre, 2010. Este trabajo forma parte del contenido de la tesis de doctorado de la autora principal para optar por el título de Doctor en Ciencias Agrícolas.

2 Instituto Nacional de Ciencias Agrícolas. Gaveta postal \#1. San José de Las Lajas. Cuba. odile@inca.edu.cu

3 Escuela Agrícola Panamericana/Zamorano. Apartado aéreo \# 93. Tegucigalpa. Honduras. jcrosas@zamorano.edu
} 
(Lema et al. 2007), dependiendo de las condiciones climáticas durante el desarrollo de cultivo del frijol, de la variedad que se cultive y del inóculo residual existente.

En Cuba esta enfermedad se encuentra ampliamente distribuida. Se conocen índices de infección en vainas hasta de un $48,5 \%$ en variedades susceptibles; estas cifras pueden llegar a ser más altas en el follaje, donde se ha informado de índices superiores al $80 \%$ (Stefanova 1996). Las pérdidas en rendimiento en Cuba, pueden oscilar entre un 17 y 57\% (Hernández 1996, Stefanova 1996), mientras que en Honduras pueden ser superiores al $40 \%$ en variedades comerciales susceptibles (Rosas 2003).

El patógeno Xcp utiliza como principal fuente de inóculo la semilla (Sheppard et al. 1989). La semilla contaminada juega un papel crucial en el ciclo de vida del tizón bacteriano y proporciona una doble función para esta bacteria: diseminación y supervivencia (Zaumeyer y Meiners 1957, Rava et al. 1996).

El desarrollo de variedades resistentes contra la invasión del patógeno o contra niveles altos de severidad de la enfermedad es uno de los objetivos de los programas de mejoramiento (Pastor-Corrales y Schwartz 1994).

Uno de los resultados más relevantes en el mejoramiento para la resistencia a Xcp fueron las líneas "XAN 159", "XAN 160", "XAN 161" las cuales fueron desarrolladas de un cruce entre $P$. vulgaris y $P$. acutifolius (PI 319443) por la Universidad de Riverside - California (Mc Elroy 1985, Beebe y Pastor-Corrales 1991). La línea "XAN 159" permitió recuperar un número de genes de resistencia en sus accesiones, (Mc Elroy 1985). En trabajos desarrollados por Singh y Muñoz (1999); Lema et al. (2007) reportaron las líneas VAX 1, VAX 2 VAX 3, VAX 4, VAX 5 y VAX 6 con alta resistencia a aislamientos de $X c p$.

La efectividad del uso de la resistencia genética para el control de $X c p$ constituye la mejor alternativa en el control fitosanitario de este patógeno, por ser una tecnología relativamente barata y lo cual permite que los agricultores cuenten con variedades con diferentes niveles de resistencia a este patógeno (Rodríguez 2002). El objetivo de este trabajo fue: 1) evaluar la reacción de genotipos de frijol común, procedentes de Cuba y de Honduras, al tizón bacteriano aislamiento EAP 9506 de Honduras; 2) identificar nuevas líneas y variedades con tolerancia a este aislamiento.

\section{MATERIALES Y MÉTODOS}

\section{Sitio experimental}

Esta investigación se desarrolló en el invernadero del área experimental del Programa de Investigaciones en frijol (PIF), Escuela Agrícola Panamericana, Zamorano, Honduras, ubicada a $805 \mathrm{msnm}$. Esta localidad presenta una temperatura promedio anual de $24^{\circ} \mathrm{C}$ y $1100 \mathrm{~mm}$ de precipitación promedio anual.

\section{Material experimental}

Se evaluó la reacción de genotipos de frijol al aislamiento EAP9506 de Xcp de Honduras. En el Experimento 1 se evaluó la reacción de 37 genotipos de frijol procedentes de Cuba, incluyendo 18 variedades comerciales y tres pre comerciales, 14 accesiones de Vivero de Fuentes de Resistencia (VIFURE) del Centro Internacional de Agricultura Tropical (CIAT), y como testigo resistente fue utilizada la variedad XAN 112 y como susceptible BAT 93 (Rodríguez 2002). Los materiales fueron inoculados con el aislamiento EAP 9506 y la severidad se evaluó con base en la escala de uno a nueve. En el Experimento 2, se evaluaron 27 accesiones del PIF de Honduras (17 líneas de la cruza Tío Canela 75/VAX6 y ocho variedades mejoradas procedentes del Centro Internacional de Agricultura Tropical (CIAT), Colombia), incluyéndose como testigos las variedades Catrachita y VAX3, susceptible y resistente a $X c p$, respectivamente (Zabala 2003).

\section{Siembra}

Las plantas se sembraron en maceteros de seis pulgadas cúbicas con un sustrato de suelo: arena esterilizado con vapor, a razón de tres maceteros por variedad. Se sembraron cuatro semillas de cada genotipo por macetero. Durante la conducción del experimento se suministró a las plantas el riego necesario, se realizó el control de plagas con trampas adhesivas amarillas ubicadas en diferentes lugares del invernadero.

\section{Inoculación}

El inóculo se preparó con un cultivo del aislamiento EAP 9506 de $X c p$, aislado de plantas de frijol colectadas en la localidad de Namasigue, Choluteca, Honduras. 
Este crecimiento bacterial se sembró y se incubó a $28^{\circ} \mathrm{C}$ por 48 horas en medio de cultivo YDC compuesto por extracto de levadura, carbonato de calcio, dextrosa y agar bacteriológico (Sheppard et al. 1989). Se preparó una suspensión acuosa de las bacterias a una concentración de $3 \times 10^{7} \mathrm{ufc} / \mathrm{ml}$, la cual se determinó con base en la escala de McFarland (Zabala 2003). La inoculación de las plantas se realizó a los 14 días después de la siembra (DDS), utilizando el método de punción múltiple (Pastor-Corrales et al. 1981); el cual consiste en presionar el folíolo central del primer trifolio con una base sólida dispuesta de agujas impregnadas de inóculo.

\section{Evaluación de la severidad}

Las plantas se evaluaron a partir de los 34 DDS, correspondiente a la etapa fenológica V4.. Los síntomas se identificaron visualmente con una escala de severidad de 1 a 9 , donde $1=$ tejido sano y $9=$ tejido muerto. En esta escala las plantas con calificación de 1 a 3 se consideran de reacción resistente, de 4 a 6 de reacción intermedia y de 7 a 9 de reacción susceptible (CIAT 1981). Se realizaron seis evaluaciones de severidad y se determinó el valor de la media de éstas.

\section{RESULTADOS Y DISCUSIÓN}

\section{Evaluación de accesiones de frijol procedentes de Cuba (Experimento 1)}

\section{Variedades comerciales}

En este estudio, todos los genotipos procedentes de Cuba evaluados con el aislamiento EAP 9506 presentaron reacciones intermedias y susceptibles (Cuadro 1). Es importante resaltar que de las variedades comerciales estudiadas ninguna obtuvo valores de severidad inferiores a seis, esto nos permite calificarlas como materiales de reacción entre intermedia y susceptible. Se destacaron las variedades Velasco Largo, M112, Guama 23, Holguín 518, Chevere y la variedad pre-comercial CUT 53, con valores de reacción entre 6 y 6,8 , superiores a los obtenidos por el testigo XAN $112(5,8)$.

De las reacciones de las accesiones del VIFURE incluidas en este experimento; la línea XAN 159
Cuadro 1. Reacción de accesiones de Cuba al aislamiento EAP 9506 de $X c p$ de la media de seis evaluaciones. Escuela Agrícola Panamericana, Zamorano, Honduras. 2007.

\begin{tabular}{|c|c|c|}
\hline Identificación & Procedencia & $\begin{array}{c}\text { Media de } \\
\text { seis evalua- } \\
\text { ciones }\end{array}$ \\
\hline CC $25-9(N)$ & V. Comercial & 9,0 \\
\hline Bolita 42 & V. Comercial & 7,0 \\
\hline Ica Pijao & V. Comercial & 9,0 \\
\hline BAT 304 & V. Comercial & 7,5 \\
\hline Tazumal & V. Comercial & 7,3 \\
\hline Holguín 518 & V. Comercial & 6,8 \\
\hline Velasco Largo & V. Comercial & 6,5 \\
\hline Red Kloud & V. Comercial & 7,0 \\
\hline M-112 & V. Comercial & 6,6 \\
\hline CC 25-9 (R) & V. Comercial & 9,0 \\
\hline Hatuey 24 & V. Comercial & 7,1 \\
\hline Guama 23 & V. Comercial & 6,6 \\
\hline Bonita 11 & V. Comercial & 9,0 \\
\hline Chévere & V. Comercial & 6,6 \\
\hline BAT 93 (Engañador) & V. Comercial & 7,0 \\
\hline Delicias 364 & V. Comercial & 7,0 \\
\hline Guira 89 & V. Comercial & 7,0 \\
\hline Rosa & V. Comercial & 7,0 \\
\hline AFR 362 & VIFURE & 6,1 \\
\hline AFR 603 & VIFURE & 6,3 \\
\hline NY 793755-2 & VIFURE & 6,6 \\
\hline CORNELL 10392 BULK. & VIFURE & 6,5 \\
\hline L 81-61 (JUTIAPA) & VIFURE & 6,0 \\
\hline PI 325761 & VIFURE & 4,5 \\
\hline RXAH 182741-C & VIFURE & 5,0 \\
\hline XAN 91 & VIFURE & 4,6 \\
\hline XAN 155 & VIFURE & 7,3 \\
\hline XAN 159 & VIFURE & 2,3 \\
\hline XAN 273 & VIFURE & 7,0 \\
\hline XAN 280 & VIFURE & 6,1 \\
\hline XAN 286 & VIFURE & 6,5 \\
\hline XR 16633 & VIFURE & 7,0 \\
\hline CUT 53 & V. precomerciales & 6,3 \\
\hline CUT 49 & V. precomerciales & 7,0 \\
\hline CUT 45 & V. precomerciales & 7,0 \\
\hline XAN 112 (Testigo 1) & V. comercial & 5,8 \\
\hline BAT 93 (Testigo 2) & V. comercial & 7,0 \\
\hline
\end{tabular}

V. comercial: Variedad comercial.

V. precomercial: Variedad precomercial.

VIFURE: Vivero de Fuentes de Resistencia a bacteriosis común. 
$(3,0)$, resultó ser la variedad con mayor resistencia al aislamiento. El resto de los genotipos de este vivero presentaron reacciones de susceptibilidad (7,0-9,0). El testigo BAT 93, presentó daños severos en el follaje ( everidad $>8$ ) lo que demuestra su susceptibilidad a este aislamiento. En este grupo, se destacan las líneas PI 325761, RXAH 182741-C y XAN 91, con valores de reacción intermedia de severidad (4,5-5), inferiores a los obtenidos por el testigo XAN $112(5,8)$. Otras variedades como AFR 362, AFR 603, NY 793755-2, Cornell 10392 BULK L 81-61, XAN 280 y XAN 286 presentaron reacción intermedia $(6,1-6,6)$.

\section{Evaluación de accesiones de frijol de Honduras (Experimento 2)}

Las evaluaciones realizadas a las 16 líneas procedentes de la cruza de Tío Canela/Vax 6 (Cuadro 2), nos permitió confirmar que todas las reacciones observadas fueron de resistencia al aislamiento EAP9506 superando al valor obtenido por los testigos Tío Canela y Catrachita $(8,8)$. Se destaca la línea X0104-45-3-5-5 con el valor más alto de resistencia a este aislamiento $(2,3)$.

Al observar el comportamiento de las líneas del CIAT, se destacan los genotipos VAX 6, VAX 3, VAX

Cuadro 2. Reacción de accesiones de frijol común del Zamorano al aislamiento EAP 9506 de $X c p$ de la media de seis evaluaciones. Escuela Agrícola Panamericana, Zamorano, Honduras. 2007.

\begin{tabular}{|c|c|c|c|c|}
\hline No. & Identificación & País & Procedencia & $\begin{array}{c}\text { Media de seis eva- } \\
\text { luaciones }\end{array}$ \\
\hline 1 & Oreol & Honduras & Tío Canela x VAX 6 & 2,8 \\
\hline 3 & X069-157-8-5-2-5 & Honduras & Tío Canela x VAX 6 & 3,0 \\
\hline 4 & X069-153-9-4-3-2 & Honduras & Tío Canela x VAX 6 & 2,6 \\
\hline 5 & X069-153-9-4-3-3 & Honduras & Tío Canela x VAX 6 & 3,5 \\
\hline 6 & Х069-153-9-4-3-5 & Honduras & Tío Canela x VAX 6 & 3,3 \\
\hline 7 & X069-157-12-5-1-4 & Honduras & Tío Canela x VAX 6 & 3,6 \\
\hline 8 & X069-157-14-4-1-3 & Honduras & Tío Canela x VAX 6 & 2,8 \\
\hline 9 & X069-157-14-4-3-1 & Honduras & Tío Canela x VAX 6 & 3,3 \\
\hline 10 & X069-157-14-4-5-5 & Honduras & Tío Canela x VAX 6 & 3,0 \\
\hline 11 & X0104-37-5-3-4 & Honduras & Tío Canela x VAX 6 & 2,6 \\
\hline 12 & X0104-38-2-1-1 & Honduras & Tío Canela x VAX 6 & 3,6 \\
\hline 13 & X0104-45-3-5-5 & Honduras & Tío Canela x VAX 6 & 2,3 \\
\hline 14 & X0104-45-5-1-4 & Honduras & Tío Canela x VAX 6 & 2,5 \\
\hline 15 & $\mathrm{X} 0104-52-5-5-3$ & Honduras & Tío Canela x VAX 6 & 2,8 \\
\hline 16 & $X 0104-52-5-5-5$ & Honduras & Tío Canela x VAX 6 & 3,3 \\
\hline 17 & $\mathrm{X} 0104-52-5-5-6$ & Honduras & Tío Canela x VAX 6 & 3,6 \\
\hline 18 & $\mathrm{X} 0104-52-5-6-2$ & Honduras & Tío Canela x VAX 6 & 3,3 \\
\hline 19 & Tío Canela 75 (testigo) & Honduras & Tío Canela x VAX 6 & 8,8 \\
\hline 20 & Catrachita (testigo) & Honduras & Variedad & 8,8 \\
\hline 21 & VAX 1 & Colombia & CIAT & 4,1 \\
\hline 22 & VAX 2 & Colombia & CIAT & 5,0 \\
\hline 23 & VAX 3 & Colombia & CIAT & 2,5 \\
\hline 24 & VAX 4 & Colombia & CIAT & 6,1 \\
\hline 25 & VAX 5 & Colombia & CIAT & 2,6 \\
\hline 26 & VAX 6 & Colombia & CIAT & 1,8 \\
\hline 27 & XAN 309 & Colombia & CIAT & 2,3 \\
\hline 28 & XAN 310 & Colombia & CIAT & 3,1 \\
\hline
\end{tabular}

ISSN: 1021-7444 
5, XAN 309, y XAN 310, con reacciones de resistencia al aislamiento EAP9506. Las accesiones VAX 4, VAX 1, VAX 2 presentaron reacción intermedia $(4,1-6,1)$, a las obtenidas por los testigos Tamaulipas y Catrachita, con susceptibilidad a este aislamiento (severidad $>8,0$ ).

En anteriores evaluaciones realizadas en Cuba, se observaron reacciones de resistencia en los genotipos XAN 155; XAN 159; XAN 280; XAN 286; "CUT 53"; "CUT 49" y "CUT 45"; con los valores de reacción más bajos, inferiores incluso a los obtenidos por los testigos resistentes XAN 112 y BAT 93 (Rodríguez et al. 1999, Rodríguez 2002). Las diferencias entre los resultados de este experimento y los obtenidos en Cuba por Rodríguez et al. (1999) y Rodríguez (2002), pudieran estar determinados por la diferencia en virulencia de los aislamientos de $X c p$ utilizados, siendo el más virulento el EAP9506 de Honduras. Barrera (2001) y Zabala (2003) reportaron resistencia a aislamientos de Honduras en las líneas X0104- 45-3-5-5, X069-153-9-4-3, X069-157- 14-4-1-3, X0104-37-53-4, X0104- 45-5-1-4 y X0104-52- 5-5-3 (severidad $<2,8$ ); mientras en los testigos Tío Canela 75 y Catrachita, se registraron reacciones de susceptibilidad (severidad> 8) al aislamiento EAP9506 de Xcp.

En estudios de resistencia al aislamiento EAP 9506, Zabala (2003) obtuvo resultados similares, destacando la resistencia de las líneas VAX 3 y VAX 6. La variedad Catrachita es utilizada como testigo susceptible en estudios de resistencia a Xcp en Honduras.

En estudios de patogenicidad de varios aislamientos de Xcp de la región realizados por Wolfang (1999) y Zabala (2003), se reporta al aislamiento EAP 9506 como el de mayor virulencia de la colección del de Zamorano.

Existen genotipos que tienen un fuerte componente de resistencia vertical; sin embargo, este puede ser afectado cuando las plantas consideradas como resistentes se exponen a aislamientos del patógeno diferentes en patogenicidad. Por ello, es importante utilizar un amplio rango de patogenicidad de $X c p$ en los programas de mejoramiento genético del frijol (Navarrete y Acosta 2000).

Los resultados obtenidos en esta investigación son similares a los señalados por Singh (1992), Acosta y Navarrete (1996), Cruz et al. (2004), quienes afirman que algunos genotipos considerados como resistentes en una región o país, se muestran susceptibles a los aislamientos de $X c p$ de otras regiones. Así mismo, la resistencia que presentan algunos genotipos clasificados como resistentes puede ser inestable; esto confirma que existe una alta especificidad de la interacción entre los genotipos del patógeno y del hospedero.

Se han identificado genotipos con resistencia a la cepa de $X c p$ estudiada. Estos tienen mucho valor en los programas de fitomejoramiento para la incorporación de resistencia a Xcp. En el caso de Cuba, se puede tener en cuenta a XAN 159 como posible padre donante de resistencia a este patógeno en los trabajos de mejora genética. Sin embargo, la introducción de nuevas líneas con resistencia a Xcp como X 0104- 45-3-5-5, X 069-153-9-4-3 , X 069-157- 14-4-1-3, X 0104-37-5-34, X 0104- 45-5-1-4 y X 0104-52- 5-5-3, resultaría ser más efectivo, porque estas líneas poseen además genes de resistencia a enfermedades causadas por el virus del mosaico dorado amarillo del frijol y tienen mejor adaptación al trópico que las línea XAN 159.

\section{LITERATURA CITADA}

Acosta, GJA; Navarrete, MR. 1996. Search for multiple disease resistance common bean. Ann. Rep. Bean. Improv. Coop. 39:47-59.

Barrera, C. 2001. Uso de técnicas convencionales para el mejoramiento genético de la resistencia a la bacteriosis común y al virus del mosaico dorado amarillo del frijol común. Tesis Ing. Agrónomo. Escuela Agrícola Panamericana. Zamorano, Honduras. 44 p.

Beebe, SE; Pastor-Corrales, MA. 1991. Breeding for disease resistance. In van Schoonhoven, A; Voysest, O. eds. Common beans: Research for Crop Improvement. C. A. B. International y CIAT, Walling ford, UK. p. 561-617.

Campos, AJ. 1987. Enfermedades del frijol. Ed. Trillas. México, DF. 132 p.

CIAT (Centro Internacional de Agricultura Tropical). 1981. Aislamiento del patógeno. In Enfermedades bacterianas del frijol: Identificación y control. Guía de estudio. Cali. Colombia. p. 11-13.

Cruz, I; Ramírez, RV; García, RE, Castillo. FG; Sandoval, JSI. 2004. Selección para resistencia a tizón común en frijol. Rev. Fitotecnia Mexicana 27(2):144-147.

Hernández, T. 1996. El cultivo del frijol (Phaseolus vulgaris L.) y la bacteriosis común (Xanthomonas campestris pv. phaseoli) en Cuba. In PROFRIJOL. ed. I Taller 
sobre bacteriosis común de frijol. Universidad de Puerto Rico RUM. PROFRIJOL. p. 199-201.

Lema, M; Teran, H; Sinhg, SP. 2007. Selecting common bean with genes of different evolutionary origins for resistance to Xanthomonas campestris pv. phaseoli. Crop Science 47:1367-1374.

Mc Elroy, JB. 1985. Breeding dry beans (Phaseolus vulgaris L) for common bacterial blight resistance derived from Phaseolus acutufolius A. Gray. Ph.D Thesis, Cornell univ, Ithaca. New York. 45 p.

Navarrete, R; Acosta-Gallegos, JA. 2000. Resistencia del frijol al tizón de halo en el valle de México y progreso de la enfermedad. Rev. Fitotec. Mex. 2:17-28.

Pastor, MA; Beebe, S; Correa, FJ. 1981. Comparing two techniques for evaluating resistance in beans to Xanthomonas campestris pv. phaseoli. Proc. Firsth Int. Conf. Plant Path. Bact. Cali, Colombia. p. 493-503.

Pastor, MA; Beebe, S; Correa, FJ. 1981. Comparing two inoculation techniques for evaluating resistance in beans to Xanthomonas campestris pv. phaseoli. In Proc. Fifth Int. Conf. Plant Path. Bact. J. C. Lozano, Ed. Centro Internacional de Agricultura Tropical (CIAT), Cali, Colombia y University of Missouri, Columbia, EEUU, Cali. p. 493-503.

Pastor, MA; Schwartz, YH. 1994. Problemas de producción del frijol en los trópicos. 2 ed. CIAT, Colombia. 734 p.

Rava, AC; Da Costa, CGJ; Sartorato, A; Zimmermann, OMJ. 1996. Obtencao de linhgens de feijeiro resistentes ao crestamento bacteriano común originadas do cruzamento entre Phaseolus vulgaris e P. acutifolius. Summa. Phytopathologica 22(1):33-36.

Rodríguez, MO; Faure, B; Benítez, R; Carballo, MR. 1999. Avances en el estudio de la bacteriosis común del frijol. Agronomía Mesoamericana 10(1):55-58.

Rodríguez, MO. 2002. Caracterización de aislamientos de Xanthomonas axonopodis pv. phaseoli y su empleo en la selección de genotipos resistentes a bacteriosis común. Tesis de maestro en Ciencias Biológicas. Universidad de la Habana. Cuba. 74 p.

Rosas, JC. 2003. El cultivo del frijol común en América Tropical. Escuela Agrícola Panamericana, Zamorano, Honduras, Imprenta Litocom, Tegucigalpa, Honduras. $57 \mathrm{p}$.

Sheppard, JW; Roth, D; Saettler, A. 1989. Detection of Xanthomonas campestris pv. phaseoli in bean. In Saettler, AW; Schaad, NW; Roth, DA. eds. Detection of bacteria in seed and other planting material. APS Press. St. Paul, Minn. p. 17-29.

Singh, SP. 1992. Common bean improvement in the tropics. Plant Breeding Reviews 10:199-269.

Singh, PS; Muñoz, GC. 1999. Resistance to common bacterial blight among Phaseolus species and common beans improvement. Crop Science 39(1):80-89.

Stefanova, M. 1996. Aspectos etiológicos y epidemiológicos de la bacteriosis común (Xanthomonas campestris pv. phaseoli) de frijol en Cuba. In PROFRIJOL. ed. I Taller Internacional sobre bacteriosis común del Frijol. Univ. de Puerto Rico. PROFRIJOL. p. 121-129.

Wolfgang, B. 1999. Identificación de fuentes de resistencia utilizando aislamientos hondureños de Xanthomonas campestris pv. phaseoli y su importancia en el manejo de la bacteriosis común del frijol. Tesis Ing. Agrónomo. Escuela Agrícola Panamericana. Zamorano, Honduras. 29 p.

Zabala, PS. 2003. Resistencia genética del frijol común a aislamientos de Xanthomonas axonopodis pv. phaseoli de Honduras. Tesis Ing. Agrónomo. Escuela Agrícola Panamericana. Zamorano, Honduras. 31 p.

Zaumayer, WI; Meiners, JP. 1957. A monografic study of beans and methods for their control, U. S. Dep. Agric. Tech. Bul. 255 p. 